\title{
SARCOMA DE KAPOSI EN PACIENTE CON DIAGNÓSTICO TARDÍO DE VIH. PRESENTACIÓN DE UN CASO Y REVISIÓN.
}

\section{KAPOSI'S SARCOMA IN PATIENTS WITH LATE HIV DIAGNOSIS. CASE REPORT AND REVIEW OF LITERATURE.}

María Belén Castaño ${ }^{1}$, Débora Litvack², Ingrid Natalia Videla ${ }^{3}$, Mónica Herrero ${ }^{4}$, Susana Pereyra ${ }^{5}$.

\section{Resumen:}

El sarcoma de Kaposi es un tumor linfoangioproliferativo descripto por primera vez en el año 1872 por Moritz Kaposi. Hay cuatro variantes clínicas, la forma clásica, la endémica, la iatrogénica asociada a trasplante o inmunosupresión y la epidémica asociada a SIDA, de la cual se hará referencia en esta publicación. Se describe un paciente varón de 31 años, al cual durante la misma internación se hace el diagnóstico de SIDA y de sarcoma de Kaposi.

Palabras clave: sarcoma de Kaposi; SIDA; VIH.

\section{Abstract:}

Kaposi's sarcoma is a limphoangioproliferous tumor described for the first time in the year 1872 by Moritz Kaposi. There are four clinical variants, the classical form, the endemic, the iatrogenic associated to transplantation or immunosuppression and the epidemic associated with AIDS, which will be referred in this publication. In this research,(case, paperwork, investigation) a 31 year old male patient, who was diagnosed AIDS and Kaposi's sarcoma at the same time while in hospital, is described.

Keywords: Kaposi's sarcoma; AIDS; HIV.

\footnotetext{
${ }^{1}$ Residente de $2^{0}$ año de dermatología, Hospital Córdoba. Email de contacto: mbelen.castano@hotmail.com.ar

${ }^{2}$ Residente de $3^{\circ}$ año de dermatología, Hospital Córdoba.

${ }^{3}$ Residente de $1^{\circ}$ año de dermatología, Hospital Córdoba.

${ }^{4}$ Anatomopatóloga de planta del servicio de anatomía patológica, Hospital Córdoba.

5 Jefa del servicio de dermatología, Hospital Córdoba.
} 


\section{Introducción}

El sarcoma de Kaposi (SK) es un tumor linfoangioproliferativo, del cual se describen cuatro variantes clínicas (clásica, endémica, iatrogénica y epidémica). Presentamos un caso de SK epidémico en paciente con diagnóstico reciente de SIDA.

\section{Caso clínico}

Caso clínico: Paciente de sexo masculino de 31 años de edad, oriundo de Córdoba Capital. Sin antecedentes personales patológicos hasta el momento. Presentó una lesión en piel constatada durante la internación por la que se solicitó una interconsulta. Al examen físico exhibía una placa eritemato- violácea, infiltrada, única, de bordes difusos y consistencia duro elástica (imagen 1 y 2).

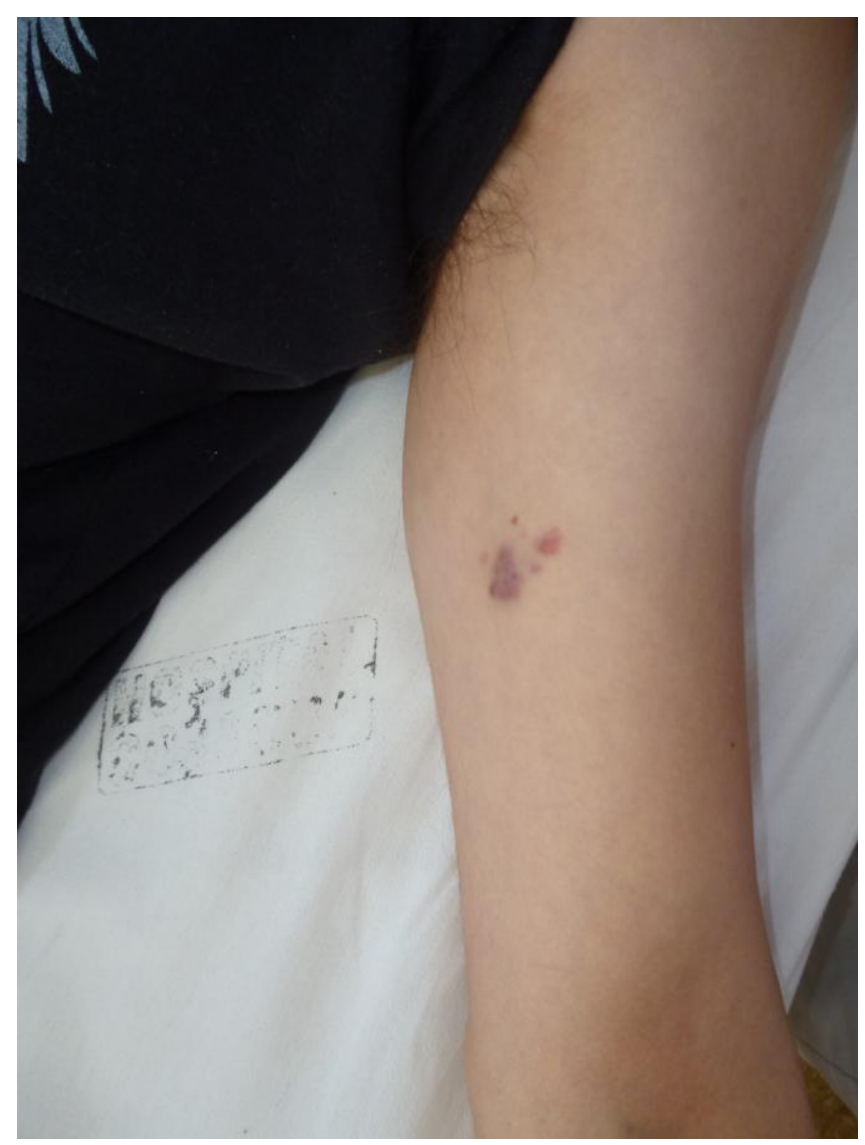

Imagen 1. Placa eritemato- violácea, infiltrada, única, de bordes difusos y consistencia duro elástica.

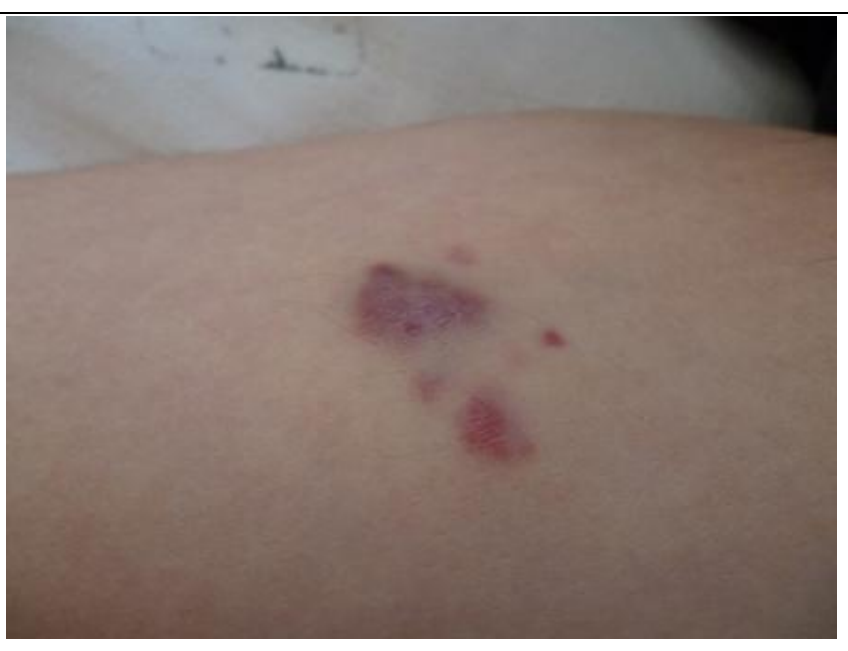

Imagen 2. Placa eritemato- violácea, infiltrada, única, de bordes difusos y consistencia duro elástica.

Localizada en brazo izquierdo, asintomática, de un año y medio de evolución. No presentaba lesiones en mucosas. El paciente ingresó al nosocomio por disminución de la agudeza visual y cefalea hemicránea de dos meses de evolución asociada a pérdida de peso sin fiebre u otros síntomas acompañantes. Se decidió la internación para realización de métodos complementarios con el diagnóstico presuntivo de papilitis bilateral. Los resultados positivos obtenidos en el laboratorio fueron: leucopenia, con 3300/ mm3 glóbulos blancos (neutrófilos en banda $20 \%$, neutrófilos segmentados $28 \%$, linfocitos $20 \%$, monocitos $6 \%$, eosinófilos $20 \%$, basófilos $2 \%$ ), VSG $80 \mathrm{~mm} /$ hora, serología para VIH (ELISA) positiva con una carga viral de 36000 copias y recuento de linfocitos T CD 4 de $11 \mathrm{cel} / \mathrm{mm}^{3}$. Las serologías para hepatitis $B$ y $C$, CMV $Y$ VEB fueron negativas y la VDRL no reactiva. Se decidió realizar una biopsia incisional de la lesión. En la histopatología con hematoxilina/ eosina se evidenció a menor aumento epidermis normal y lesión vascular que comprometía dermis superficial y profunda (imagen 3). 


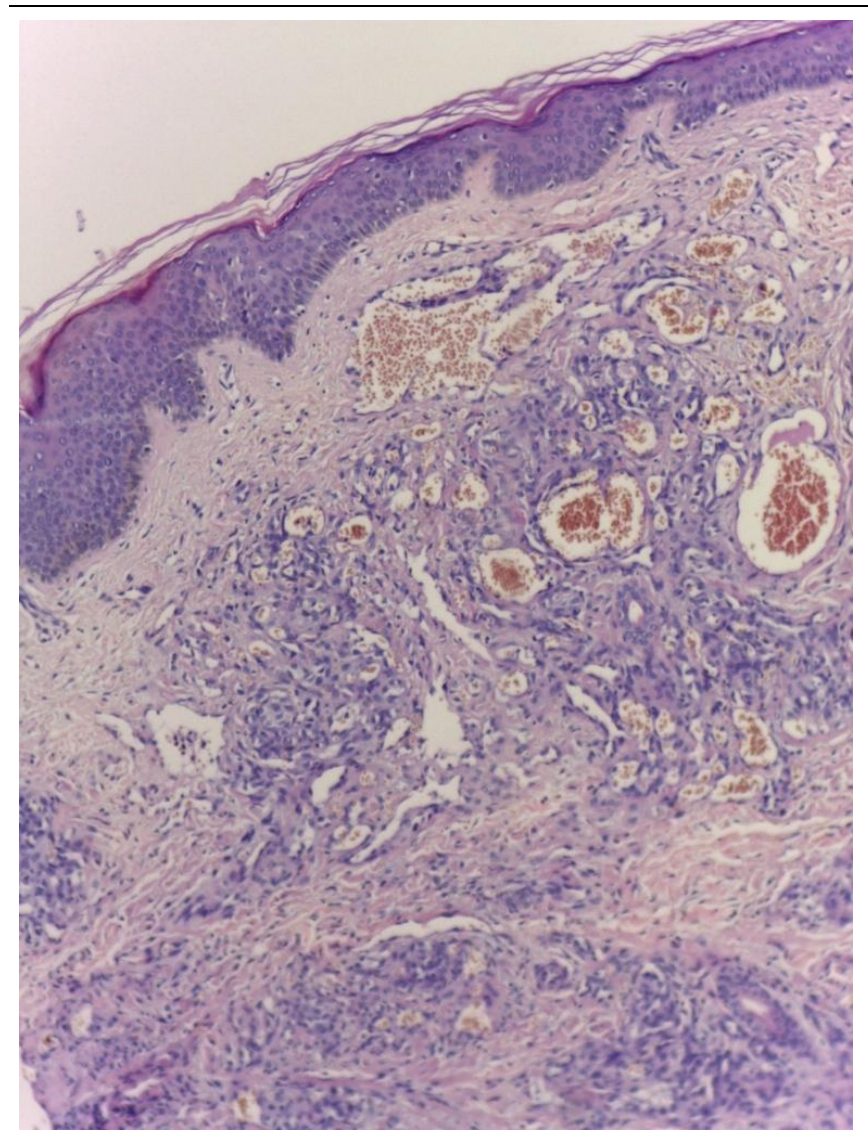

Imagen 3. Con tinción de hematoxilina/ eosina a menor aumento se observa epidermis normal y lesión vascular que compromete dermis superficial y profunda.

A mayor aumento espacios vasculares interconectados y capilares revestidos por endotelio con núcleos hipercrómicos, frecuentes focos de extravasación eritrocitaria, células fusadas con núcleos pleomorfos, contornos irregulares y citoplasma escaso (imagen 4).

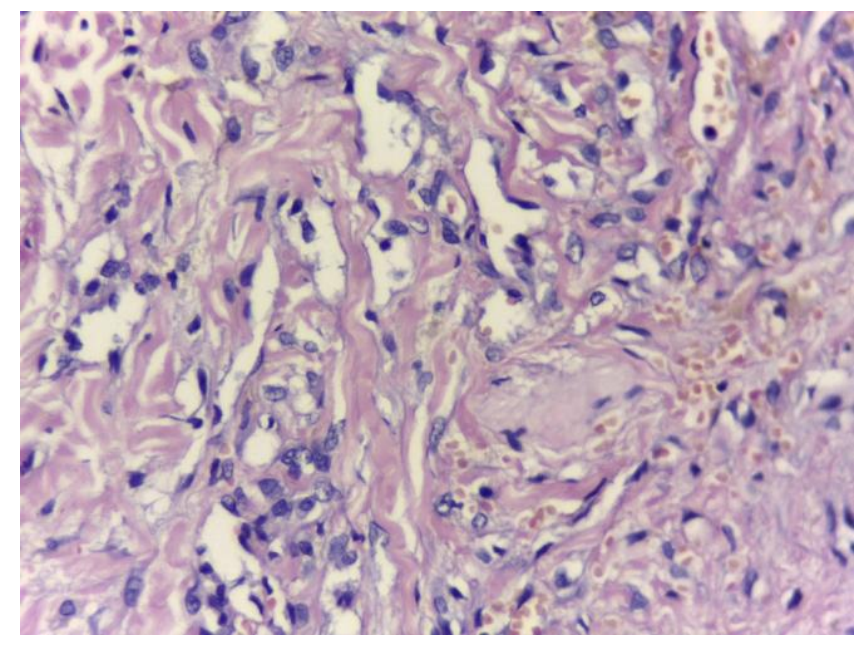

Imagen 4. A mayor aumento espacios vasculares interconectados y capilares revestidos por endotelio con núcleos hipercrómicos,

frecuentes focos de extravasación eritrocitaria, células fusadas con núcleos pleomorfos, contornos irregulares y citoplasma escaso.
Se llegó al diagnóstico clínico e histopatológico de sarcoma de Kaposi en paciente con diagnóstico reciente y tardío de $\mathrm{VIH}$, SIDA. Se indicó comenzar con terapia antirretroviral y ganciclovir $500 \mathrm{mg}$ cada 12 hs por vía endovenosa y mantener una conducta expectante respecto al sarcoma de Kaposi.

\section{Comentarios}

El sarcoma de Kaposi (SK) es un tumor linfoangioproliferativo descripto por primera vez en el año 1872 por Moritz Kaposi, a partir de cinco casos de una enfermedad hasta entonces desconocida y potencialmente mortal, cuya denominación fue "sarcoma pigmentado múltiple idiopático cutáneo", que posteriormente tomó el nombre de $\mathrm{SK}^{1}$. En la década de los 80 se diagnostican los primeros casos de SK asociado a síndrome de inmunodeficiencia adquirida (SIDA), afectando con mayor frecuencia a varones infectados ${ }^{2}$. El SK presenta cuatro variantes clínicas, el SK clásico más frecuentemente en la séptima década de la vida, en hombres con ascendencia mediterránea 0 judía, comienza en forma localizada y progresa con lentitud. Tienden a progresar lentamente y evolucionan a placas firmes, luego a nódulos. El desarrollo suele ser benigno, presentando una evolución lenta, de tres a ocho años ${ }^{3}$. El SK endémico africano, se manifiesta con mayor frecuencia en algunos países de África Central. Predomina en hombres, entre los 35 a 39 años. Se divide en otros subtipos clínicos como nodular con curso clínico similar al SK clásico; algunas formas más agresivas: florida e infiltrativa y el subtipo linfadenopático que se presenta en niños y puede ser letal ${ }^{3,4}$. El SK iatrogénico se presenta en pacientes con compromiso de su inmunidad, como en pacientes trasplantados, oncológicos 0 afectos de enfermedades autoinmunes en tratamiento inmunosupresor. Se manifiesta a una edad menor respecto al SK clásico, puede existir afectación ganglionar y visceral aunque la afectación cutánea sigue siendo la más frecuente $^{3,4}$. EI SK epidémico relacionado a SIDA es del cual haremos hincapié en esta publicación. En el $60 \%$ de los casos afecta la piel y la mucosa orofaríngea, en piel tiene topografía predominante en extremidades inferiores presentándose bajo la forma de máculas de color rojo-violáceo, placas de forma y tamaño irregular, puede haber vesículas o ampollas, e incluso neoformaciones de tamaño variable, algunas de aspecto verrugoso o vegetante, y generalmente es asintomático. Si existe afectación en el tronco, las lesiones siguen una distribución blaschkoide. Puede ser la manifestación inicial de la 
enfermedad en un $15 \%$ de estos casos. Estos pacientes pueden presentar también afectación extracutánea: gastrointestinal, pulmonar y ganglionar, ${ }^{4}$. En cuanto a la afectación de mucosas las lesiones en mucosa bucal son en el $22 \%$ de los pacientes la primera manifestación y representa un marcador para recuento de linfocitos T CD $4+$ menor a 200/ $\mu \mathrm{L}$. La localización más frecuente es en paladar duro y aparece como una mácula violácea, que evoluciona a pápulas y nódulos con un aspecto en empedrado. También aparecen lesiones en paladar blando, úvula, faringe, encías y lengua. Son infrecuentes las lesiones conjuntivales. En cuanto a su fisiopatogenia, en 1994 se detectó la presencia del herpes virus $8(\mathrm{HVH}-8)$ en el $90 \%$ de las lesiones de SK asociado con infección por $\mathrm{VIH}$. Este virus pertenece a la familia $\mathrm{Y}^{-}$ herpesviridae, genero Rhadinovirus y es el responsable directo de todas las variantes del SK. Se sabe que constituye un factor necesario pero no suficiente para el desarrollo del mismo y que otros factores como la predisposición genética, los factores ambientales y la inmunosupresión tendrían un rol importante ${ }^{1,6}$. Para que el ADN viral produzca transformación en la célula huésped deben ocurrir dos fenómenos: el ADN viral debe integrarse al genoma del huésped y posteriormente debe producirse un cambio en la expresión genómica de la célula huésped. El HVH-8 integrado al genoma celular se encuentra en un estado latente, permitiendo la expresión continua de oncogenes o la disminución de la expresión de genes supresores tumorales sin producir muerte celular. El virus codifica diversas proteínas homólogas a oncoproteínas humanas lo que permite un aumento en la expresión de genes virales con potencial oncogénico y aumento de la concentración de factor de crecimiento fibroblástico b libre (factor angiogénico) ${ }^{7}$. La confirmación diagnostica de SK es histológica. La anatomía patológica no varía entre sus diferentes formas clínicas, pero sí en sus distintos estadios evolutivos. Se distinguen tres hallazgos característicos: angiogénesis, inflamación y proliferación. Con hematoxilina-eosina, se observan células fusiformes distribuidas en dermis que dibujan luces vasculares irregulares. Puede haber extravasación hemática. Los restos de hematíes degradados pueden formar los glóbulos hialinos, que son estructuras esféricas, eosinófilas y PAS positivas. No son exclusivos del sarcoma de kaposi ya que pueden observarse en granulomas piógenos, tejido de granulación y angiosarcomas. La histología varía en función de la fase clínica macula, placa y tumor. Así en los estadíos iniciales o placa, los hallazgos histológicos son poco llamativos, con infiltrado perivascular linfoplasmocitario en dermis superficial y profunda que incluso puede llevar a confusión con dermatosis inflamatorias. A medida que las lesiones se transforman en placas y nódulos, se produce un aumento de la celularidad fusocelular con luces vasculares irregulares. Puede haber atipias y mitosis, aunque a pesar de ser un tumor maligno no se caracteriza por presentar un índice mitótico muy elevado $^{3,6}$. Las técnicas de inmunohistoquímica pueden ayudar en el diagnóstico, especialmente en lesiones incipientes o dudosas. Las luces vasculares son de origen linfático y se marcan con el anticuerpo D2-40 que marca endotelio linfático. Otros marcadores de endotelio vascular, no linfático pueden ser positivos como CD 31 y CD $34^{3}$.

El diagnóstico diferencial clínico debe plantearse con la angiomatosis bacilar, angiosarcomas y hemangiomas. Las formas nodulares de SK deben diferenciarse también de esporotricosis e infecciones por micobacterias atípicas. Otro diagnóstico diferencial es el pseudosarcoma de Kaposi o acroangiodermatitis. Se trata de una entidad descripta en pacientes amputados, pacientes en hemodiálisis con fístulas arteriovenosas, en pacientes infectados por virus hepatitis $\mathrm{C}$ o en asociación con malformaciones vasculares, se presenta como pápulas violáceas que afectan el tercio más distal de extremidades inferiores, pueden ser uni o bilaterales $y$ ulcerarse y sangrar ${ }^{4}$. En cuanto al tratamiento, localmente consisten en escisión local (eficaz en lesiones pequeñas y únicas), destrucción local con nitrógeno liquido (indicada en nódulos que protruyen y están profundamente pigmentados), laser o terapia fotodinámica y tratamiento tópico con acido 9-cis-retinoico. La radioterapia puede ser eficaz en la enfermedad localizada en sitios del organismo difíciles de alcanzar de otra manera 0 en el SK más avanzado. La quimioterapia citotóxica intralesional con vinblastina $(0,1 \mathrm{mg}$ inyectados por centímetro cuadrado de lesión) más eficaz en lesiones papulosas, tempranas y pequeñas) y también se han utilizado vincristina y bleomicina ${ }^{3,8}$. Cuando apareció, a mediados de 1990 el tratamiento antirretroviral muy activo (HAART) se observó una disminución de la incidencia de SK asociado a sida y una frecuente remisión de las lesiones tempranas del SK durante el tratamiento. Sin embargo, no es suficiente si aparecen lesiones diseminadas o compromiso de otros órganos por lo que es preciso agregar quimioterapia. Las antraciclinas liposómicas mostraron ser más eficientes y mejor toleradas que los tratamientos combinados (bleomicina y vincristina o ambas 
combinadas con doxorrubicina) ${ }^{3}$. Se han estudiado ampliamente en el tratamiento del SK asociado a VIH. No existen protocolos estandarizados, pero la mayoría eligen a la doxorubicina liposomal pegilada como agente quimioterápico, considerándose fármaco de primera elección a no ser que exista contraindicación cardíaca. La dosis es de $20 \mathrm{mg} /$ $\mathrm{m}^{2}$ cada tres semanas. La duración del tratamiento tampoco está estandarizada. La vinblastina tiene como efecto secundario la mielosupresión. La vincristina es menos tóxica,por lo cual se dan alternadas. La bleomicina se puede administrar intramuscular 0 endovenosa (esta última con mayor respuesta). $\mathrm{Si}$ no hay respuesta a la doxorubicina, los fármacos usados de segunda línea son vinblastina sola 0 en combinación con bleomicina, etopósido y gemcitabina ${ }^{4}$ EI interferon $\alpha$ utlizado como pilar de tratamiento para SK diseminado asociado a SIDA durante la década del 80 todavía resulta una opción para estos pacientes que reciben HAART. La reducción de la masa tumoral es dosis dependiente y se necesitan dosis mayores a $20 \mathrm{x}$ $106 \mathrm{U} / \mathrm{m}^{2}$ con lo que los efectos adversos producidos por el interferon son mayores ${ }^{3,4}$. Por lo tanto todo paciente con SK debe iniciar la terapia antirretroviral (TARV) con un inhibidor de proteasa (IP) asociado, ya que los IP demostraron inhibir la angiogénesis del tumor. La etapa precoz del SK se define si el paciente cumple todos los siguientes criterios: SK limitado a la piel con mínimo compromiso de mucosa oral (máculas sólo en el paladar duro), CD4 > $200 / \mathrm{mm}^{3}$, sin infecciones oportunistas, sin candidiasis oral y sin síntomas B. En estos casos, el tratamiento puede realizarse sólo con TARV que incluya IP. Por el contrario, en la etapa tardía, definida como pacientes con SK que cumplan cualquiera de los siguientes criterios: SK pulmonar o gastrointestinal, compromiso oral excesivo, ulceraciones tumorales, CD4 < 200, paciente con historia de infecciones oportunistas, síntomas B (pérdida de peso, fiebre y sudores nocturnos), el tratamiento debe realizarse con TARV que incluya IP asociado a antraciclinas liposomales como doxorubicina. El valganciclovir podría ser una alternativa en la prevención del SK debido a que ha mostrado suprimir al VHH-8. Sin embargo, se trata de evidencia experimental y muy precoz ${ }^{9}$.

\section{Conclusión}

Presentamos un caso de sarcoma de Kaposi en un paciente con diagnóstico tardío de $\mathrm{VIH}$, el tumor más frecuente en estos pacientes. Si bien en la actualidad la etiología no se conoce con exactitud, la infección por el virus herpes 8 y la inmunodepresión en estos pacientes son considerados factores para su desarrollo. Con la incorporación desde el año 1990 del tratamiento antirretroviral muy activo se ha observado una disminución de la incidencia y la morbimortalidad en los pacientes con sarcoma de kaposi asociado a $\mathrm{VIH}$ y remisión de las lesiones tempranas.

\section{Bibliografía}

1. Rothlin A, Arias M, Abeldaño A. Sarcoma de Kaposi en pacientes trasplantados. Dermatología Argentina. Vol 18, no 4. 2012.

2. Pereyra E, Aída G, et al. Sarcoma de Kaposi bucal en pacientes con trasplante de riñón. MEDISAN [online]. Vol.19, n.2 [citado 2015-09-15], pp. 192-198. 2015.

3. Tschachler E. Sarcoma de kaposi y angiosarcoma. En Fitzpatrick. Goldsmith, Katz, Gilchrest. Et ál. Dermatología en medicina general. Ed. Panamericana, Buenos Aires. 1481- 1488, 2012.

4. Hernández Ruiz E, García-Herrera A, Ferrando J. Sarcoma de Kaposi. Med Cutan Iber Lat Am; 40 (2): 3948. 2012.

5. López L, Corte Casarreal L, Navarrete Franco G. Sarcoma de Kaposi en paciente VIH. Presentación de un caso. Rev Cent Dermatol Pascua. Vol. 16, Núm. 2. 2007.

6. Rothlin A, Meik S, Ferrari M, López Santoro C, et al. Sarcoma de Kaposi en SIDA. Tratamiento con HAART y paclitaxel en tres casos de SK/SIDA con buena respuesta. Dermatología Argentina, Vol 17, No 6. 2011.

7. González P, Chouela E, Consalvo, L. Sarcoma de Kaposi. Arch. Argent. Dermatol. 53:285-288, 2003.

8. Wolff, $K$, Johnson R. Linfomas y sarcomas cutáneos. Fitzpatrick Atlas en color y sinopsis de dermatología clínica. $6^{\circ}$ edición. $1^{\circ}$ reimpresión. Ed. Panamericana, Buenos Aires. 2014.

9. Navarrete-Dechent, $C$, et al . Manifestaciones dermatológicas asociadas a la infección por VIH/SIDA. Rev. chil. infectol., Santiago, v. 32, supl. 1, p. 57-71, feb. 2015. 